13

\title{
Сравнение характеристик волноводных рефрактометрических сенсоров
}

\author{
(C) В.И. Наливайко ${ }^{1}$, М.А. Пономарева ${ }^{1,2, q}$ \\ ${ }^{1}$ Институт автоматики и электрометрии Сибирского отделения РАН, \\ 630090 Новосибирск, Россия \\ ${ }^{2}$ Новосибирский государственный технический университет, \\ 630073 Новосибирск, Россия \\ I e-mail: ponomareva@iae.nsk.su \\ Поступила в редакцию 15.08.2019 г. \\ В окончательной редакции 15.08.2019 г. \\ Принята к публикации 09.09.2019 г.
}

Проведен анализ работы трех типов волноводных рефрактометрических сенсоров: интерферометрического Маха-Цендера, интерферометрического двухмодового и решеточно-волноводного. Рассмотрены конструктивные особенности этих сенсоров с разделением по функциональным блокам. Рассчитаны габаритные размеры сенсоров на основе халькогенидных стекол для получения одинакового предела обнаружения для газовой анализируемой среды.

Ключевые слова: рефрактометрический сенсор, решеточный элемент ввода, халькогенидное стекло, предел обнаружения, чувствительность.

DOI: $10.21883 /$ OS.2019.12.48702.249-19

\section{Введение}

Области применения химических и биосенсоров охватывают множество потенциальных приложений, включая медицинскую, продовольственную и водную безопасность, мониторинг окружающей среды, национальную безопасность и другие. Оптические сенсорные системы на основе волноводов представляют особый интерес в связи с их универсальностью и высокой помехозащищенностью [1]. Одним из важнейших параметров волноводных сенсоров является предел обнаружения, который напрямую связан с величиной показателя преломления волноводов. В связи с этим волноводные материалы с высоким показателем преломления привлекли внимание к разработке таких сенсоров [2-4].

В настоящей работе проводится сравнение характеристик трех основных конфигураций волноводных сенсоров: интерферометрического Маха-Цендера [5], интерферометрического двухмодового [6] и решеточноволноводного [7] (рис. 1). Рассматриваемые сенсоры являются рефрактометрическими. Анализируемое вещество на поверхности волновода изменяет эффективный показатель преломления распространяющейся волноводной моды. Контроль изменения эффективного показателя волноводной моды реализуется тремя различными способами:

- в интерферометрическом сенсоре Маха-Цендера (рис. $1, a$ ) входная волноводная мода разделяется между двух оптических каналов, в плече одного из которых происходит взаимодействие с анализируемым веществом, и измеряется разность фаз волноводных мод обоих каналов после их объединения;
- в интерферометрическом двухмодовом сенсоре (рис. $1, b)$ один оптический волноводный канал, но в нем распространяются две волноводные моды разного порядка, которые получают различающиеся фазовые задержки в процессе взаимодействия с анализируемым веществом;

- в решеточно-волноводном сенсоре (рис. 1,c) при изменении эффективного показателя преломления волноводной моды изменяется угол ввода волноводной моды в волновод, который является измеряемым параметром сенсора.

\section{Конструктивные особенности волноводных сенсоров}

Каждый из рассматриваемых ниже волноводных сенсоров состоит из следующих функциональных областей.

1. Входная область - элемент ввода излучения в волновод, отвечающий за формирование волноводной моды;

2. Коммуникационная область - волновод, обеспечивающий прохождение волноводной моды от анализируемого вещества до измерителя;

3. Чувствительная область - участок на поверхности волновода, в котором осуществляется контакт волноводной моды с анализируемым веществом;

4. Измерительная область - детектор изменения интенсивности волноводной моды на выходе сенсора.

Рассмотрим реализацию этих областей для каждого из рассматриваемых типов сенсоров и укажем их особенности. 

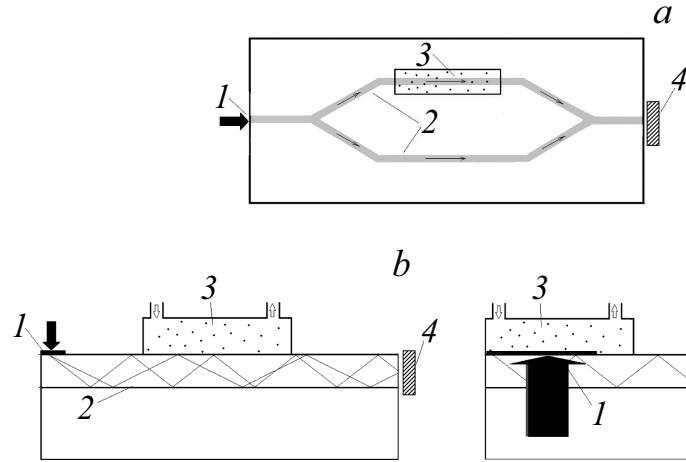

$b$

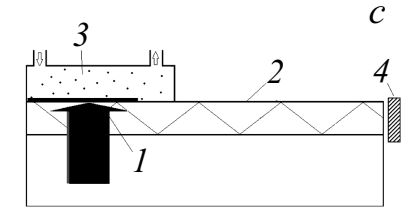

Рис. 1. Конфигурации оптических волноводных сенсоров: интерферометрического Маха-Цендера $(a)$, интерферометрического двухмодового $(b)$ и решеточно-волноводного $(c)$. Функциональные области сенсоров: 1 - входная, 2 - коммуникационная, 3 - чувствительная, 4 - измерительная.

\section{1. Входная область}

В интерферометрическом сенсоре Маха-Цендера волноводная мода может вводиться любым из доступных способов ввода $[8]$ - через торец волновода, с помощью дифракционной решетки, призмы и другими способами.

В интерферометрическом двухмодовом сенсоре с помощью вводного элемента необходимо одновременно ввести две когерентные волноводные моды разного порядка со сравнимыми по величине интенсивностями. Способы ввода двух мод в волновод рассматривались нами ранее [9].

В решеточно-волноводном сенсоре элементом ввода является дифракционная решетка, которая одновременно выполняет роль чувствительного элемента [10]. И при этом ширина входного пучка должна быть согласована с длиной решетки с помощью расширителя оптических пучков.

\section{2. Коммуникационная область}

В интерферометрическом сенсоре Маха-Цендера волноводная мода распространяется по канальным волноводам, изготовление которых требует высокого уровня технологии. Волновод разделяется на два канала, в которых распространяются опорная и сигнальная волноводные моды. Анализируемое вещество влияет на интенсивность и фазу сигнальной волноводной моды. На выходе эти два канала объединяются и измеряется результат интерференции этих пучков. Для исключения влияния мод высоких порядков желательно, чтобы канальный волновод был одномодовым.

В интерферометрическом двухмодовом сенсоре обе волноводные моды распространяются по одному волноводу. Волновод может быть планарным и должен поддерживать не меньше двух волноводных мод. Влияние мод более высоких порядков также является нежелательным.

В решеточно-волноводном сенсоре не накладываются ограничения на количество мод, поддерживаемых волноводом. Волновод может быть многомодовым, так как функцию фильтра мод выполняет вводная дифракционная решетка.

\section{3. Чувствительная область}

В чувствительной области обеспечивается контакт анализируемого вещества с волноводной модой. Для этого необходима рабочая камера, в которой анализируемое вещество изолировано от окружающей среды. Так как все три типа сенсоров используют явление интерференции оптических пучков, длина чувствительной области определяет предел обнаружения сенсора в целом. Конструкция чувствительной области зависит от физико-химических свойств анализируемого вещества и не зависит от типа рассматриваемых сенсоров.

\section{4. Измерительная область}

Интенсивность волноводных мод на выходе сенсоров обычно измеряется с помощью фотодетекторных регистраторов. Фотодетектор устанавливается вблизи выходного торца волновода или вблизи поверхности волновода в области выводного элемента сенсора.

В табл. 1 отмечены варианты реализации и главные конструктивные особенности рассматриваемых сенсоров.

В приложениях необходимо учитывать особенности условий эксплуатации сенсоров. Например, температурные градиенты недопустимы для интерферометрического сенсора Маха-Цендера, в то время как двухмодовые и волноводно-решеточные сенсоры более стабильны в таких же условиях. Однако двухмодовые и решеточноволноводные сенсоры требуют использования более сложных конструкций элементов ввода, одновременного ввода двух мод и широкого вводного пучка соответственно.

\section{Характеристики волноводных сенсоров}

Наиболее важной характеристикой сенсора является его предел обнаружения, т.е. минимально измеряемое количество анализируемого вещества. Поскольку рассматриваемые нами сенсоры являются рефрактометрическими, они регистрируют изменение показателя преломления анализируемого вещества, соответствующее изменению его концентрации. Переход к измерению концентрации анализируемого вещества проводится с помощью калибровочных проб.

Волновод сенсора характеризуется волноводной чувствительностью, которая определяет изменение эффективного показателя преломления волноводной моды в зависимости от изменения показателя преломления анализируемого вещества при контакте с волноводом в чувствительной области:

$$
S=\frac{\partial N}{\partial n_{c}},
$$

где $N$ - эффективный показатель преломления волноводной моды, $n_{c}$ - показатель преломления анализируе- 
Таблица 1. Реализация функциональных областей волноводных сенсоров

\begin{tabular}{l|l|l|l}
\hline \multirow{2}{*}{ Область } & \multicolumn{2}{|c}{ Сенсор } \\
\cline { 2 - 4 } & \multicolumn{1}{|c}{$\begin{array}{c}\text { интерферометрический } \\
\text { Маха-Цендера }\end{array}$} & \multicolumn{1}{c}{$\begin{array}{c}\text { интерферометрический } \\
\text { двухмодовый }\end{array}$} & \multicolumn{1}{c}{$\begin{array}{c}\text { решеточно- } \\
\text { волноводный }\end{array}$} \\
\hline \multirow{2}{*}{ Входная } & $\begin{array}{l}\text { Любой известный } \\
\text { элемент ввода } \\
\text { излучения в волновод }\end{array}$ & $\begin{array}{l}\text { Элемент ввода для одновременного } \\
\text { когерентного возбуждения } \\
\text { двух волноводных мод }\end{array}$ & $\begin{array}{l}\text { Решеточный } \\
\text { элемент ввода }\end{array}$ \\
\hline Коммуникационная & $\begin{array}{l}\text { Два канальных } \\
\text { одномодовых волновода } \\
\text { с Ү-соединениями }\end{array}$ & $\begin{array}{l}\text { Планарный } \\
\text { двухмодовый волновод }\end{array}$ & $\begin{array}{l}\text { Нет ограничений на тип } \\
\text { многомодовость волновода }\end{array}$ \\
\hline Чувствительная & $\begin{array}{l}\text { Расположена } \\
\text { в одном плече сигнального } \\
\text { канального волновода }\end{array}$ & $\begin{array}{l}\text { Расположена } \\
\text { планарного волновода }\end{array}$ & $\begin{array}{l}\text { Пространственно совпадает } \\
\text { со входной областью }\end{array}$ \\
\hline Измерительная & \multicolumn{3}{|c}{ задаваемым порогом чувствительности регистрируюшей системы }
\end{tabular}

мого вещества. Для трехслойного волновода аналитический вид чувствительности выражается как [11]

$$
S=\frac{n_{c}\left(n_{f}^{2}-N^{2}\right)}{N \gamma_{c}\left(n_{f}^{2}-n_{c}^{2}\right) h_{e f}}\left[2\left(\frac{N}{n_{c}}\right)^{2}-1\right]^{\rho},
$$

где $\rho=0$ для ТЕ-мод или $\rho=1$ для ТМ-мод, $h_{e f}-$ эффективная толщина волновода, вычисляемая по формуле

$$
h_{e f f}=h_{f}+\frac{1}{\gamma_{c}}+\frac{1}{\gamma_{s}}
$$

где $\gamma_{c, s}=\frac{2 \pi}{\lambda} \sqrt{N^{2}-n_{c, s}^{2}}\left[\left(\frac{N}{n_{f}}\right)^{2}+\left(\frac{N}{n_{c, s}}\right)^{2}-1\right]^{\rho}, n_{c}, n_{f}, n_{s}-$ показатели преломления верхней среды, волновода и подложки соответственно, $h_{f}$ - толщина волновода, $\lambda$ - длина волны света.

Для понимания физической сущности природы чувствительности волновода удобно переписать формулу (1) через долю мощности волноводной моды, распространяющейся в области с анализируемым веществом, $P_{c} / P[11]$ :

$$
S=\frac{n_{c}}{N \gamma_{c} h_{e f f}} \frac{P_{c}}{P}\left[2\left(\frac{N}{n_{c}}\right)^{2}-1\right]^{\rho} .
$$

Отсюда видно, что чем больше поле волноводной моды проникает в анализируемую среду и чем меньше толщина волновода, тем выше чувствительность волновода.

Предел обнаружения сенсора определяется волноводной чувствительностью и типом сенсора.

В интерферометрическом сенсоре Маха-Цендера измеряется разность фаз волноводных мод в двух каналах. В опорном канале фаза волноводной моды принимается постоянной, а в сигнальном канале она изменяется как

$$
\Delta \varphi=k L \Delta N
$$

где $k=2 \pi / \lambda-$ волновое число, $L-$ длина чувствительной области, $\Delta N-$ изменение эффективного показателя волноводной моды при изменении показателя преломления верхнего слоя. Продифференцировав выражение (3) по $\partial n_{c}$, имеем

$$
\frac{\partial \varphi}{\partial n_{c}}=k L \frac{\partial N}{\partial n_{c}}=k L S
$$

Отсюда получаем выражение для предела обнаружения интерферометрического сенсора Маха-Цендера:

$$
\Delta n_{c M Z}=\frac{\Delta \varphi}{k L S}
$$

Для возможности количественной оценки предела обнаружения считаем, что разность фаз измеряется с точностью $1 \%$ от $2 \pi$ [12]:

$$
\Delta \varphi=0.01 \cdot 2 \pi \text {. }
$$

Таким образом, выражение (4) можно записать как

$$
\Delta n_{c M Z}=0.01 \frac{2 \pi}{k L S} \text {. }
$$

В двухмодовом сенсоре, в отличие от интерферометрического сенсора Маха-Цендера обе волноводные моды распространяются по одному волноводу, но они поразному взаимодействуют с анализируемым веществом в чувствительной области и на выходе получают результирующую разность фаз:

$$
\Delta \varphi=\Delta \varphi_{i}-\Delta \varphi_{j}
$$

где $\Delta \varphi_{i, j}-$ фазовые задержки, получаемые $i$-й и $j$-й модами соответственно. Предел обнаружения интерферометрического двухмодового сенсора будет определяться как

$$
\Delta n_{c B M}=\frac{\Delta \varphi}{k L\left(S_{i}-S_{j}\right)}=0.01 \frac{2 \pi}{k L\left(S_{i}-S_{j}\right)} .
$$


В волноводно-решеточном сенсоре чувствительная область находится в области вводной решетки и минимальное изменение эффективного показателя преломления волноводной моды будет определяться угловой селективностью вводной решетки [10,11]:

$$
\Delta N \approx \frac{\lambda}{L_{G}}
$$

Длина чувствительной области $L$ в данном случае совпадает с длиной решетки $L_{G}$. Предел обнаружения решеточно-волноводного сенсора определяется как

$$
\Delta n_{c G W}=0.01 \frac{\Delta N}{S}=0.01 \frac{\lambda}{L_{G} S}=0.01 \frac{2 \pi}{k L_{G} S} .
$$

\section{Анализ результатов}

Как видно из выражений (5)-(7), предел обнаружения всех трех типов сенсоров зависит от двух основных параметров: волноводной чувствительности $S$ и длины чувствительной области $L$. Поэтому последовательно проанализируем влияние этих параметров на характеристики сенсоров. Как было показано ранее [9], волноводы с высоким контрастом показателей преломления обладают наибольшей чувствительностью. Поэтому для анализа выберем волноводные пленки из халькогенидного стекла $\left(n_{f}=2.5\right)$ на подложках из оксидного стекла $\left(n_{s}=1.52\right)$ в воздухе $\left(n_{c}=1\right)$.

На рис. 2 сплошными линиями показана вычисленная по формуле (1) волноводная чувствительность первых четырех мод халькогенидного волновода в зависимости от его толщины. Волноводная чувствительность падает с увеличением номера моды и толщины волновода. Расчетная оптимальная толщина одномодового волновода для обеспечения максимальной чувствительности должна составлять $50 \mathrm{~nm}$, а соответствующая этой толщине величина максимальной чувствительности равна 0.11. Предел обнаружения интерферометрического двухмодового сенсора (6) определяется разницей чувствительностей его мод. На рис. 2 штриховой линией показана разница между чувствительностями соседних волноводных мод: 0-й и 1-й (0-1), 1-й и 2-й (1-2) и 2-й и 3-й (2-3). Для двухмодового сенсора из выбранных материалов получаем оптимальную толщину двухмодового волновода $210 \mathrm{~nm}$, а соответствующую максимальную чувствительность - 0.058. Как видно, двухмодовый сенсор с точки зрения волноводного вклада в предел обнаружения сенсора примерно в два раза хуже, чем сенсор Маха-Цендера. У решеточно-волноводного сенсора ограничений на толщину волновода нет. Поэтому оптимальные значения параметров волновода такие же, как у интерферометрического сенсора Маха-Цендера: толщина волновода $-50 \mathrm{~nm}$, волноводная чувствительность -0.11 .

В интерферометрических волноводных сенсорах чем длиннее чувствительная область сенсора, тем меньше

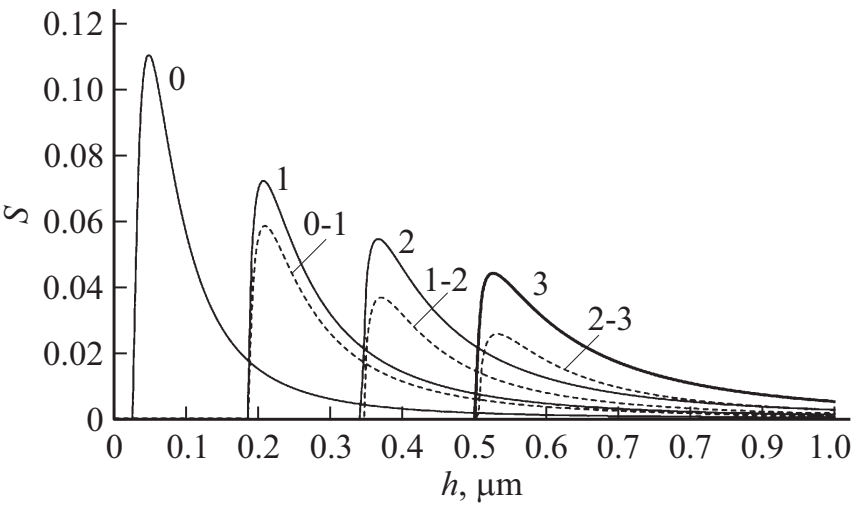

Рис. 2. Волноводная чувствительность $S$ халькогенидного волновода в зависимости от толщины волновода $h$ : сплошные кривые - чувствительности мод от 0-го до 3-го порядка, штриховые кривые $(i-j)$ - разности чувствительности между $i$ и $j$ модами $(i, j=0, \ldots, 3)$.

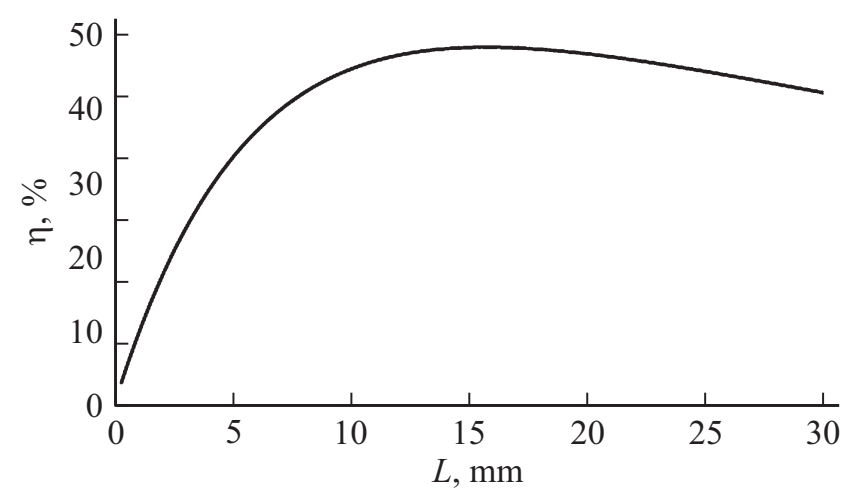

Рис. 3. Зависимость эффективности ввода $\eta$ излучения в волновод от длины вводной решетки $L$.

его предел обнаружения. Выберем для оценок длину чувствительной области $L$ сенсора Маха-Цендера, приемлемую для интегрально-оптического исполнения, равную $10 \mathrm{~mm}$. Чтобы скомпенсировать недостаток чувствительности волновода в двухмодовом сенсоре, его чувствительная область должна быть длиннее по сравнению с чувствительной областью интерферометрического сенсора Маха-Цендера. Для получения равных пределов обнаружения у этих сенсоров чувствительная область двухмодового сенсора должна быть примерно в два раза больше, чем у сенсора Маха-Цендера. Например, для выбранных значений оптимальных толщин волноводов получим соответствующую длину $L$ для двухмодового сенсора, равную $19 \mathrm{~mm}$.

В решеточно-волноводном сенсоре длина чувствительной области совпадает с длиной вводной решетки и шириной падающего пучка. Слишком большая длина вводной решетки может плохо сказаться на эффективности ввода излучения в волновод [8]. Для оценки влияния длины вводной решетки воспользуемся теорией слабо гофрированного волновода, предложенной Киселе- 
Таблица 2. Оптимальные параметры волноводных сенсоров

\begin{tabular}{l|c|c|c}
\hline \multirow{2}{*}{ Параметр } & \multicolumn{3}{|c}{ Сенсор } \\
\cline { 2 - 4 } & $\begin{array}{c}\text { нтерферометрический } \\
\text { Маха-Цендера }\end{array}$ & $\begin{array}{c}\text { интерферометрический } \\
\text { двухмодовый }\end{array}$ & $\begin{array}{c}\text { решеточно- } \\
\text { волноводный }\end{array}$ \\
\hline Оптимальная толщина волновода, $\mathrm{nm}$ & 50 & 210 & 50 \\
\hline Волноводная чувствительность & 0.11 & 0.058 & 0.11 \\
\hline Длина чувствительной области, $\mathrm{mm}$ & 10 & 19 & 10 \\
\hline Предел обнаружения, RIU & & $1.2 \cdot 10^{-5}$ &
\end{tabular}

вым [13]. Для волновода толщиной $50 \mathrm{~nm}$ и полуглубины гофра $10 \mathrm{~nm}$ при вводе излучения в край решетки получим изображенную на рис. 3 зависимость эффективности ввода от длины решетки. Видно, что при длине решеток от 10 до $30 \mathrm{~mm}$ эффективность ввода составляет приемлемую величину, равную 40-50\%. Следовательно, длина вводной решетки решеточно-волноводного сенсора и соответственно длина чувствительной области, равная $10 \mathrm{~mm}$, обеспечат получение такого же предела обнаружения, что и у сенсоров первых двух типов.

Рассчитанные по формулам (5)-(7) пределы обнаружения для всех трех типов сенсоров для приведенных выше параметров будут порядка $1.2 \cdot 10^{-5} \mathrm{RIU}$. Результаты расчетов представлены в табл. 2 .

\section{Выводы}

Результаты моделирования работы рефрактометрических сенсоров разного типа показали, что достижимый предел обнаружения оказывается сравнимым по величине для всех проанализированных типов сенсоров, несмотря на их различие в физической реализации. Разработчик вправе выбирать любой тип сенсоров для реализации в зависимости от имеющихся технологических возможностей.

Наиболее существенные различия конструктивного исполнения сенсоров состоят в следующем. Для интерферометрического сенсора Маха-Цендера необходимы канальные волноводы и два Ү-соединения. Для интерферометрического двухмодового сенсора необходим элемент ввода, обеспечивающий возбуждение двух мод одновременно. Для решеточно-волноводного сенсора необходимо расширить вводной пучок на размер чувствительной области.

При сравнении трех типов сенсоров с точки зрения предела обнаружения было показано, что в случае двухмодового сенсора толщина его волновода и длина чувствительной области должны быть увеличены в два раза для обеспечения предела обнаружения той же величины, что и в сенсорах остальных двух типов. Однако конструкция такого сенсора является наиболее стабильной и конструктивно простой.
Получаемый предел обнаружения данных сенсоров, а именно минимально измеряемое изменение показателя преломления газового анализируемого вещества, при использовании халькогенидных волноводов составляет величину $1.2 \cdot 10^{-5}$. Использование более высокоточных цифровых методов контроля в измерительной части позволит улучшить предел обнаружения по сравнению с оценкой, принятой в этой работе.

\section{Финансирование работы}

Работа выполнена в рамках госзадания Минобрнауки № гос. рег АААА-А17-117053110007-0.

\section{Конфликт интересов}

Авторы заявляют, что у них нет конфликта интересов.

\section{Список литературы}

[1] Kozma P., Kehl F., Ehrentreich-Förster E., Stamm C., Bier F.F. // Biosens. and Bioelectr. 2014. V. 58. P. 287. doi 10.1016/j.bios.2014.02.049

[2] Germann R., Salemink H.W.M., Beyeler R, Bona G.L., Horst F., Massarek I., Offrein B.J. // J. Electrochem. Soc. 2000. V. 147. P. 2237. doi 10.1149/1.1393513

[3] Gartmann Th.E., Kehl F. // Biosensors. 2015. V. 5. N 2. P. 187. doi 10.3390/bios5020187

[4] Schmitt K., Oehse K., Sulz G., Hoffmann C. // Sensors. 2008. V. 8. P. 711. doi 10.3390/s8020711

[5] Prieto F., Sepúlveda B., Calle A., Llobera A., Domínguez C., Abad A., Montoya A., Lechuga L.M. // Nanotechn. 2003. V. 14. N 8. P. 907. doi $10.1088 / 0957-4484 / 14 / 8 / 312$

[6] Zinoviev K.E., González-Guerrero A.B., Domínguez C., Lechuga L.M. // J. Lightwave Tech. 2011. V. 29. N 13. P. 1926. doi 10.1109/JLT.2011.2150734

[7] Vörös J., Ramsden J.J., Csúcs G., Szendrö I., De Paul S.M., Textor M., Spencer N.D. // Biomaterials. 2002. V. 23. I. 17. P. 3699. doi 10.1016/S0142-9612(02)00103-5.

[8] Tamir T. Integrated Optics. Berlin: Springer-Verlag, 1975. 315 р.; Тамир Т. Интегральная оптика. М.: Мир, 1978. $344 \mathrm{c}$.

[9] Наливайко В.И., Пономарева М.А. // Опт. и спектр. 2017. T. 123. № 2. C. 296. doi 10.7868/S0030403417080189 
[10] Наливайко В.И., Пономарева М.А. // Опт. и спектр. 2019. T. 126. № 4. C. 523. doi 10.21883/OS.2019.04.47523.182-18

[11] Tiefenthaler K., Lukosz W. // J. Opt. Soc. Am. B. 1989. V. 6. N 2. P. 209. doi 10.1364/JOSAB.6.000209

[12] Dante S., Duval D., Sep.lveda B., González-Guerrero A.B., Sendra J.R., Lechuga L.M. // Opt. Express. 2012. V. 20. P. 7195. doi 10.1364/OE.20.007195

[13] Киселев В.А. // Квант. электрон. 1974. Т. 1. № 7. С. 1578. 